
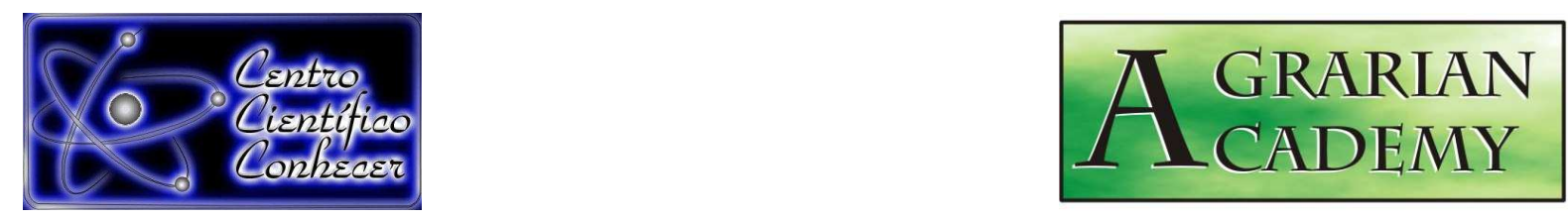

\title{
INVENTÁRIO E DIAGNÓSTICO DA ARBORIZAÇÃO URBANA DO MUNICÍPIO DE PIRANHAS - AL
}

José Thales Pantaleão Ferreira $^{1}$; Elvis Pantaleão Ferreira ${ }^{2}$; Matheus Barros da Silva $^{3}$; Francisco José S. Britto Petrauskas ${ }^{3}$; Frankly Barbosa Teotonio ${ }^{3}$

1. Professor do Curso Técnico em Agroecologia do Instituto Federal de Alagoas Câmpus Piranhas. E-mail: thales.pantaleao@ifal.edu.br

2.Mestre em Engenharia Ambiental do Instituto Federal do Espírito Santo.

${ }^{3}$ Estudante do Curso Técnico em Agroecologia do Instituto Federal de Alagoas Câmpus Piranhas.

Recebido em: 05/12/2016 - Aprovado em: 15/12/2016 - Publicado em: 31/12/2016 DOI: 10.18677/Agrarian_Academy_2016b7

\begin{abstract}
A arborização urbana é composta por toda vegetação que compõe o cenário da paisagem urbana, sendo um dos componentes bióticos mais importantes das cidades. O presente trabalho teve como objetivo gerar um inventário e diagnóstico da arborização urbana das principais avenidas no município de Piranhas - AL. A metodologia constou de visita in loco às principais avenidas da cidade para diagnostico visual da condição das árvores, do local de plantio, da necessidade de cuidados e replantio. Todas as árvores analisadas foram georreferenciadas com GPS. Os resultados mostraram uma predominância de espécies exóticas invasoras compondo a arborização urbana das principais avenidas de Piranhas, em especial de algaroba (Prosopis juliflora (Sw) DC) $(30,0 \%)$, com exceção da Avenida Sergipe que apresenta elevada quantidade de craibeiras (Tabebuia aurea). Existe pequena diversidade de espécies que compõe a arborização da paisagem urbana de Piranhas, trazendo efeito estético negativo e favorece o desenvolvimento de doenças e pragas nas árvores. Os principais problemas encontrados foram raízes danificando calçadas, necessidade de replantio, problemas com a rede elétrica e a quantidade de espécies exóticas.
\end{abstract}

RESUMO

PALAVRAS-CHAVE: Conscientização, educação ambiental, preservação.

\section{INVENTORY AND DIAGNOSIS OF THE URBAN AFFORESTATION OF THE MUNICIPALITY OF PIRANHAS - AL}

\begin{abstract}
The urban arborization is composed of all vegetation that compose the scenery of the urban landscape, being one of the most important biotic components of the cities. The present work had as objective to generate an inventory and diagnosis of the urban arborization of the main avenues in the city of Piranhas - AL. The methodology consisted of an on-site visit to the main avenues of the city for visual diagnosis of the condition of the trees, the planting site, the need for care and replanting. All the analyzed trees were georeferenced with GPS. The results show a predominance of invasive alien species composing the urban arborization of the main avenues of
\end{abstract}


Piranhas, especially of the algaroba (Prosopis juliflora (Sw) DC) (30.0\%), except Sergipe Avenue, which has a high number of crayfishes Tabebuia aurea). There is a small diversity of species that compose the afforestation of the urban landscape of Piranhas, bringing negative aesthetic effect and favors the development of diseases and pests in the trees. The main problems found were roots damaging sidewalks, need for replanting, problems with the electrical network and the amount of exotic species.

KEYWORDS: Awareness, environmental education, preservation

\section{INTRODUÇÃO}

A arborização urbana tem se tornado assunto de destaque nas cidades, principalmente com a migração de populações rurais para os centros urbanos, desenvolvendo as cidades muitas vezes de forma desordenada, gerando vários problemas que influenciam a qualidade de vida. Essa situação faz com que a população necessite cada vez mais de condições que melhorem sua convivência dentro de um ambiente muitas vezes adverso (PIVETTA \& SILVA FILHO, 2002).

É neste ambiente que a arborização urbana traz enormes benefícios para populações das cidades. Esta vegetação urbana proporciona sombra para os pedestres e veículos; gera bem estar psicológico ao homem; melhor efeito estético; protege e direciona o vento; amortece o som; amenizando a poluição sonora; reduz o impacto da água de chuva e o escorrimento superficial; auxilia na diminuição da temperatura, pois, absorve os raios solares e refresca o ambiente pela grande quantidade de água transpirada pelas folhas; melhora a qualidade do ar e preserva a fauna silvestre (PIVETTA \& SILVA FILHO, 2002).

A arborização urbana é definida como qualquer vegetação que compõe o cenário ou a paisagem urbana, sendo um dos componentes bióticos mais importantes das cidades. Tecnicamente, a arborização urbana é dividida em áreas verdes, como os parques, bosques, praças e jardins; e arborização das vias públicas (HACK et al., 2005; COPEL, 2015).

Neste mesmo contexto, observa-se que a arborização urbana ganha importância de grandes proporções principalmente para as cidades do semiárido brasileiro, localizadas no bioma caatinga que possui temperaturas médias anuais que atingem 27 a 29ํㅜ insolação média de $2.800 \mathrm{~h}^{\circ}$ ano $^{-1}$ e evaporação média de $2.000 \mathrm{~mm}$ ano-1; umidade relativa do ar média em torno de 50\%; precipitações irregulares no tempo e no espaço, concentrando-se em três a quatro meses, com médias anuais máximas de $800 \mathrm{~mm}$, apresentando alternância bem delimitada de períodos chuvosos com períodos muito secos (AB'SABER, 1996; SILVA et al., 2010).

Para se alcançarem de forma eficiente todos os benefícios da arborização urbana é essencial um planejamento, que inclui o conhecimento do patrimônio arbóreo existente, por meio de um inventário (SILVA \& GONÇALVES, 2012). Ainda segundo os autores o inventário torna-se importante para se conhecer o patrimônio arbóreo e identificar as condições atuais das espécies arbóreas e as necessidades de manejo. Neste sentido, o presente trabalho teve como objetivo realizar um pioneiro inventário e diagnóstico da arborização urbana das principais avenidas na cidade de Piranhas, Estado de Alagoas. 


\section{MATERIAL E MÉTODOS}

A presente pesquisa foi realizada no segundo semestre do ano de 2016 no município de Piranhas, localizado na região oeste do Estado de Alagoas, inserida na mesorregião do Sertão Alagoano e na microrregião Alagoana do Sertão do São Francisco. A sede do município apresenta altitude de $90 \mathrm{~m}$ e coordenadas geográficas de $9^{\circ} 37^{\prime} 38^{\prime \prime}$ de latitude sul e $37^{\circ} 45^{\prime}$ '25" de longitude oeste (Figura 1). $\mathrm{O}$ acesso a partir de Maceió é feito através das rodovias pavimentadas BR-316, BR101, AL-220 e AL-225, com percurso em torno de $285 \mathrm{~km}$.

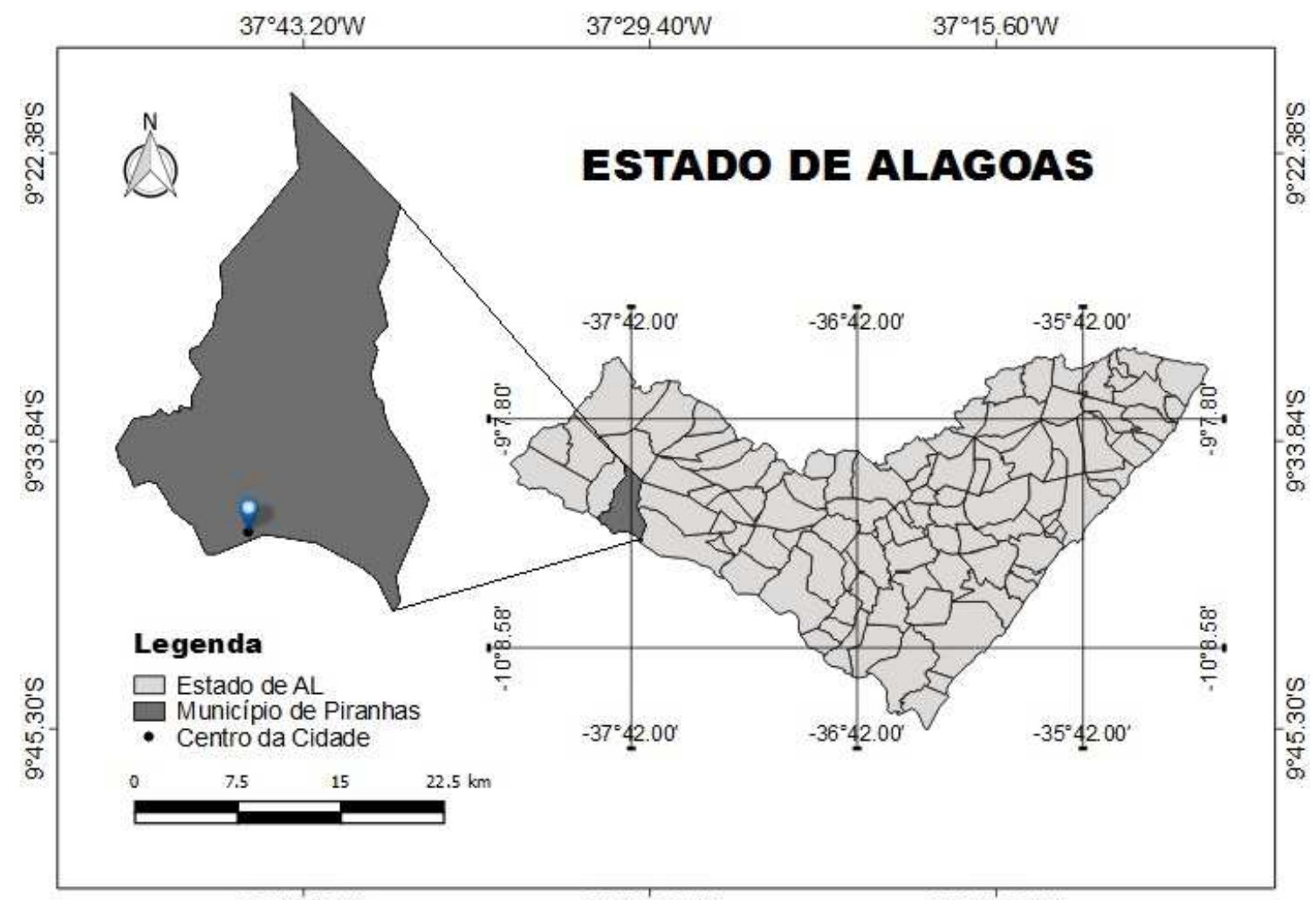

FIGURA 1. Localização espacial do município de Piranhas no Estado de Alagoas. Fonte: Os autores, (2016).

O inventário quali-quantitativo da arborização urbana das principais avenidas da cidade de Piranhas, foi realizado mediante visitas in loco, almejando a realização de diagnóstico visual e registros fotográficos da condição das árvores que compõe a arborização urbana da cidade. As avenidas avaliadas foram: i. Delmiro Gouveia, ii. Batalha, iii. Sergipe e iv. Rio São Francisco (Figura 2). 

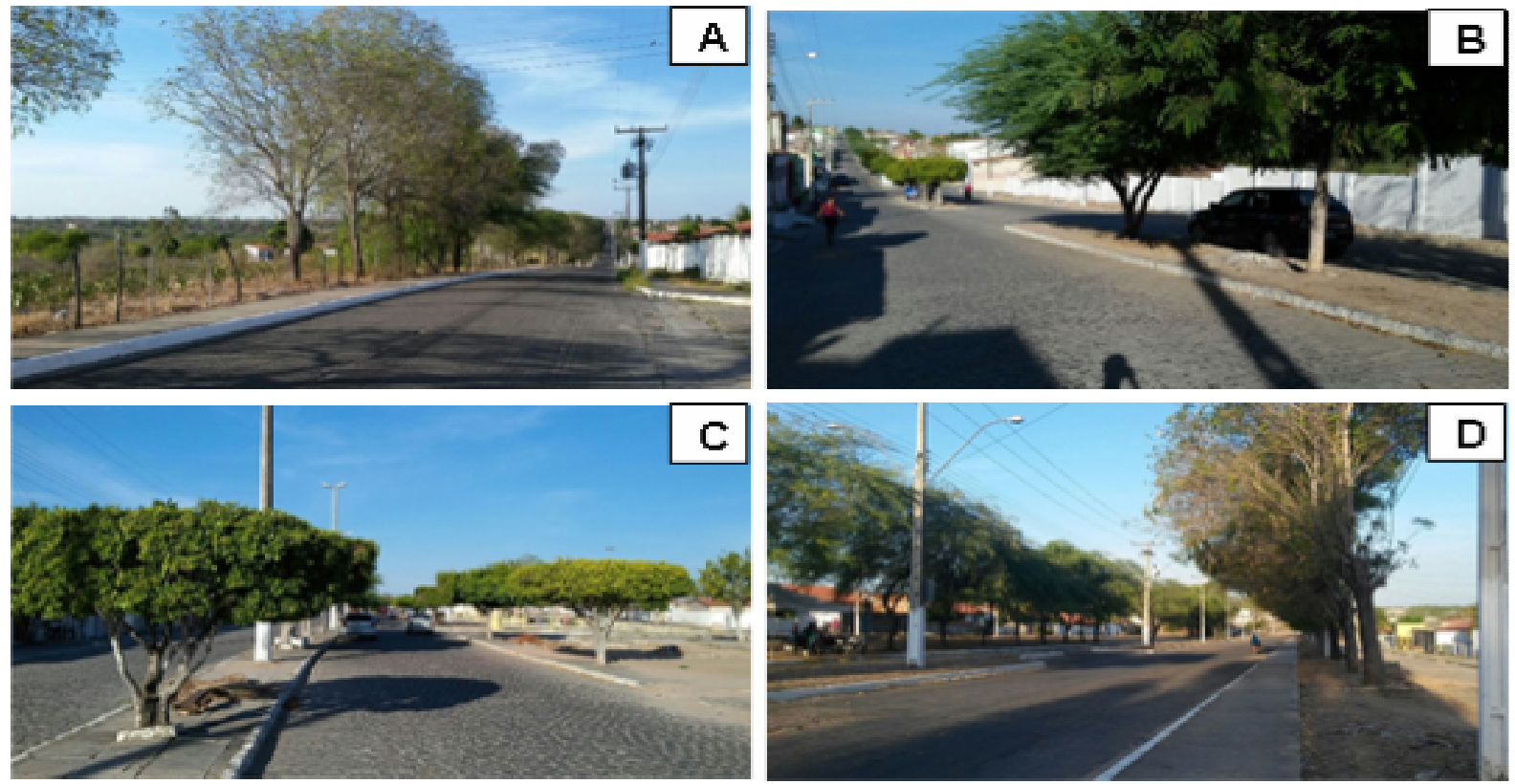

FIGURA 2. Avenidas Sergipe (A), Delmiro Gouveia (B), Batalha (C) e Rio São Francisco (D) em Piranhas - AL.

Foram avaliados o local de plantio, número de espécies, número de árvores, necessidade de replantio e necessidade de poda. Paralelamente também foi realizado o georreferenciamento das árvores e locais com necessidade de replantio utilizando o GPS Garmin Etrex 10 (Figura 3). Ao final os dados foram tabulados e organizados para melhor discussão e análise da condição da arborização urbana do município de Piranhas.

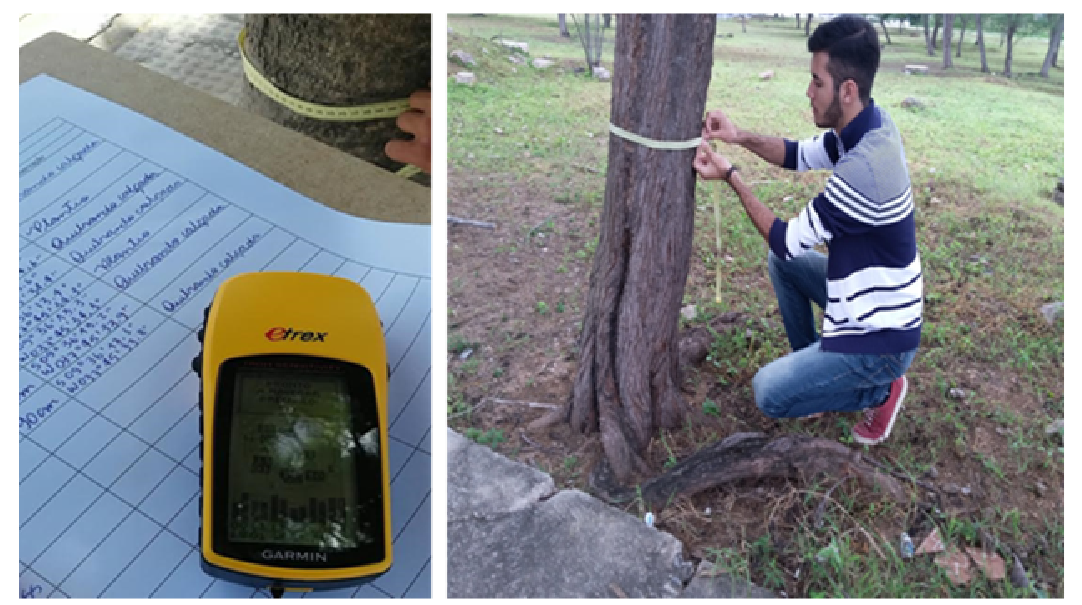

FIGURA 3. Georreferenciamento das árvores com GPS e verificação do diâmetro do caule com fita métrica.

\section{RESULTADOS E DISCUSSÃO}

O estrato arbóreo das principais avenidas no município de Piranhas no Semiárido Alagoano, é composto no total por 11 espécies de um total de 548 árvores, assim distribuídas: 194 craibeira (Tabebuia aurea) (35,5\%); 164 algaroba (Prosopis juliflora (Sw) DC) (30,0\%); 76 figueira (Ficus benjamina) (13,9\%); $39 \mathrm{nim}$ (Azadirachta indica) (7,1\%); 36 sombreiro (Clitoria fairchildiana) (6,6\%); 19 angico (Anadenanthera macrocarpa (Benth.) Brenan) (3,5\%); 11 castanheira $(2,0 \%) ; 5$ 
acácia amarela (Acacia farnesiana) (0,9\%); 2 aroeira (Schinus terebinthifolius) $(0,4 \%) ; 1$ ipê (Tabebuia) (0,2\%) e 1 mangueira (Mangifera indica) $(0,2 \%)$ (Figura 4$)$.

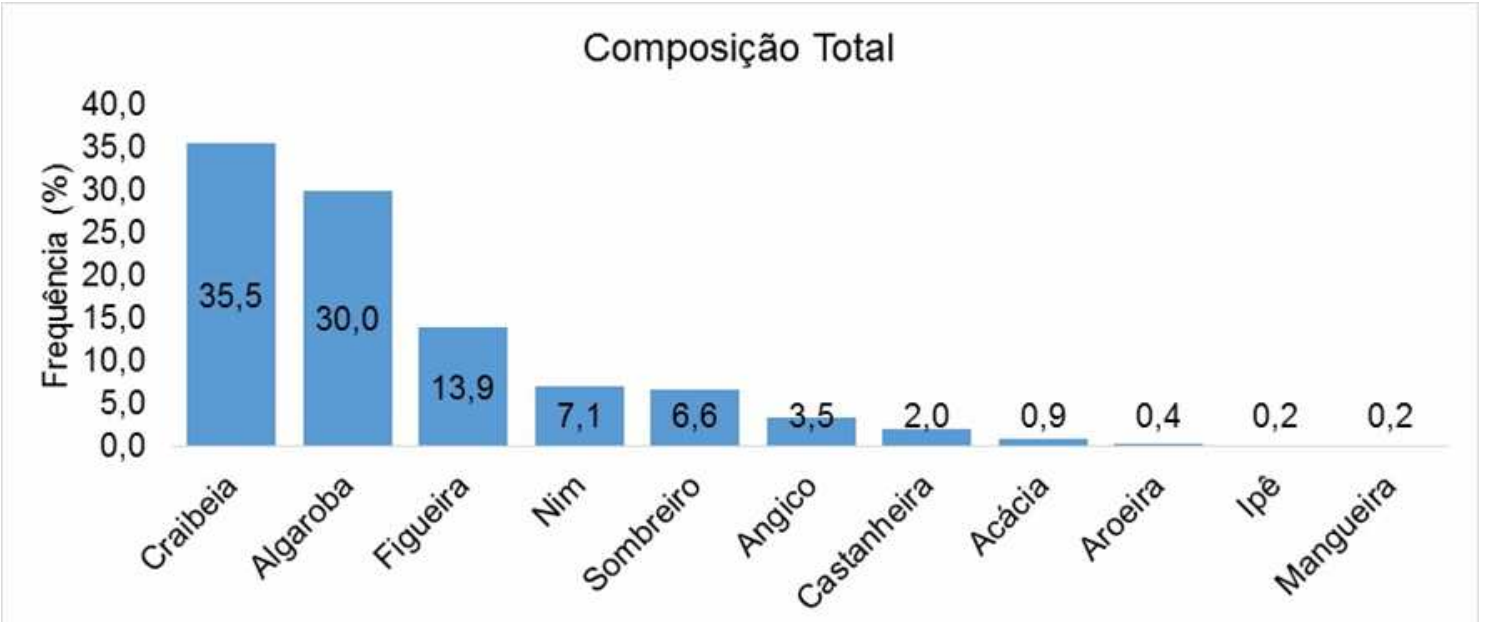

FIGURA 4. Composição total das espécies que compõe a arborização urbana.

Existe um baixo número de espécies que compõe o total de indivíduos da arborização urbana da cidade de Piranhas, fazendo com que a diversidade de espécies seja pequena (Figura 4), para LORENZO et al., (2000), este fato proporciona efeitos estéticos negativos à importância ecológica da área e favorece o desenvolvimento de doenças e pragas nas árvores. Neste contexto, dados apresentados por GREY \& DENEKE (1986); MILANO \& DALCIN (2000) advertem que em uma arborização urbana o ideal é que nenhuma espécie ultrapasse $15 \%$ do total de indivíduos da população arbórea, pois assim minimiza-se a possibilidade de desenvolvimento de pragas e doenças.

Ao analisar a Figura 4, percebe-se que duas espécies craibeira (Tabebuia aurea) e algaroba (Prosopis juliflora (Sw) DC) estão acima do limite ideal do número de indivíduos para compor a arborização urbana e juntas correspondem a $65,5 \%$ do estrato arbóreo de toda a arborização, se somar com a terceira mais frequente figueira (Ficus benjamina) esse número sobe para $74,4 \%$, comprovando a carência em diversidade de espécies e alertando para o risco fitossanitário do desenvolvimento de pragas e doenças.

Em trabalho realizado por SILVA \& GONÇALVES (2012) em Cajuri - MG, ALBERTIN et al. (2011) em Nova Esperança - PR e ALMEIDA \& BARBOSA (2010) em Cocal - RO, apenas cinco espécies foram responsáveis respectivamente por $82,5 \%, 88,3 \%$ e $85,2 \%$ de toda arborização na cidade. Sendo pior o cenário observado na cidade de Piranhas, onde as cinco espécies mais frequentes são responsáveis por $93,1 \%$ de todo estrato arbóreo urbano na cidade, mostrando a necessidade de um planejamento e readequação da arborização urbana (Figura 4).

Para SILVA \& GONÇALVES (2012) é comum encontrar cidades de diferentes portes com poucas espécies representando a grande parte dos indivíduos da população da arborização urbana, mesmo não sendo desejável por razões estéticas, ecológica e fitossanitária. Outros autores como MELO et al., (2007) reforçam o argumento que o reduzido número de espécies compondo a arborização urbana pode elevar o risco fitossanitário de disseminação de pragas e doenças nas árvores em ambiente urbano.

O inventário da arborização urbana na Avenida Delmiro Gouveia mostrou que as principais espécies são: figueira (Ficus benjamina) (50,0\%); algaroba (Prosopis AGRARIAN ACADEMY, Centro Científico Conhecer - Goiânia, v.3, n.06; p. 29 2016 
juliflora (Sw) DC) (20,9\%); nim (Azadirachta indica) (16,3\%); castanheira (9,3\%); acácia amarela (Acacia farnesiana) $(2,3 \%)$ e ipê (Tabebuia) (1,2\%) (Figura 5). A individualização da análise do componente arbóreo por Avenida em Piranhas, mostra que a situação de diversidade de espécies piora, onde três espécies juntas representam $87,2 \%$ de todo estrato arbóreo da arborização da avenida Delmiro Gouveia. Foi preocupante também constatar que as quatro primeiras espécies que juntas somam $96,5 \%$ são todas exóticas, com destaque para figueira (Ficus benjamina) com $50,0 \%$.

Segundo CARVALHO et al., (2013) a figueira (Ficus benjamina) pode causar perda de biodiversidade, não sendo também, indicada para plantio nas calçadas em função do rápido crescimento, podendo alcançar 30 metros de altura e sistema radicular agressivo que pode danificar as calçadas, rompimento e ou entupimento de tubulações, prejudicar a iluminação natural e artificial das ruas. Estes mesmos autores catalogaram 3.064 árvores da espécie Ficus benjamina na cidade de Serra Talhada no Semiárido Pernambucano causando os citados problemas.

As plantas exóticas invasoras ao se adaptarem ao novo ambiente, ocupam o espaço das espécies nativas, pois se reproduzem e promovem alterações nos processos ecológicos naturais que favorecem a sua dominância após certo período de tempo (BRAND, 2006; BLUM, 2008). Segundo os mesmos autores a introdução de exóticas invasoras é a segunda maior causa de perda da biodiversidade no planeta e os seres humanos são um dos principais responsáveis pela disseminação, podendo afetar a biodiversidade, a economia e a saúde das pessoas.

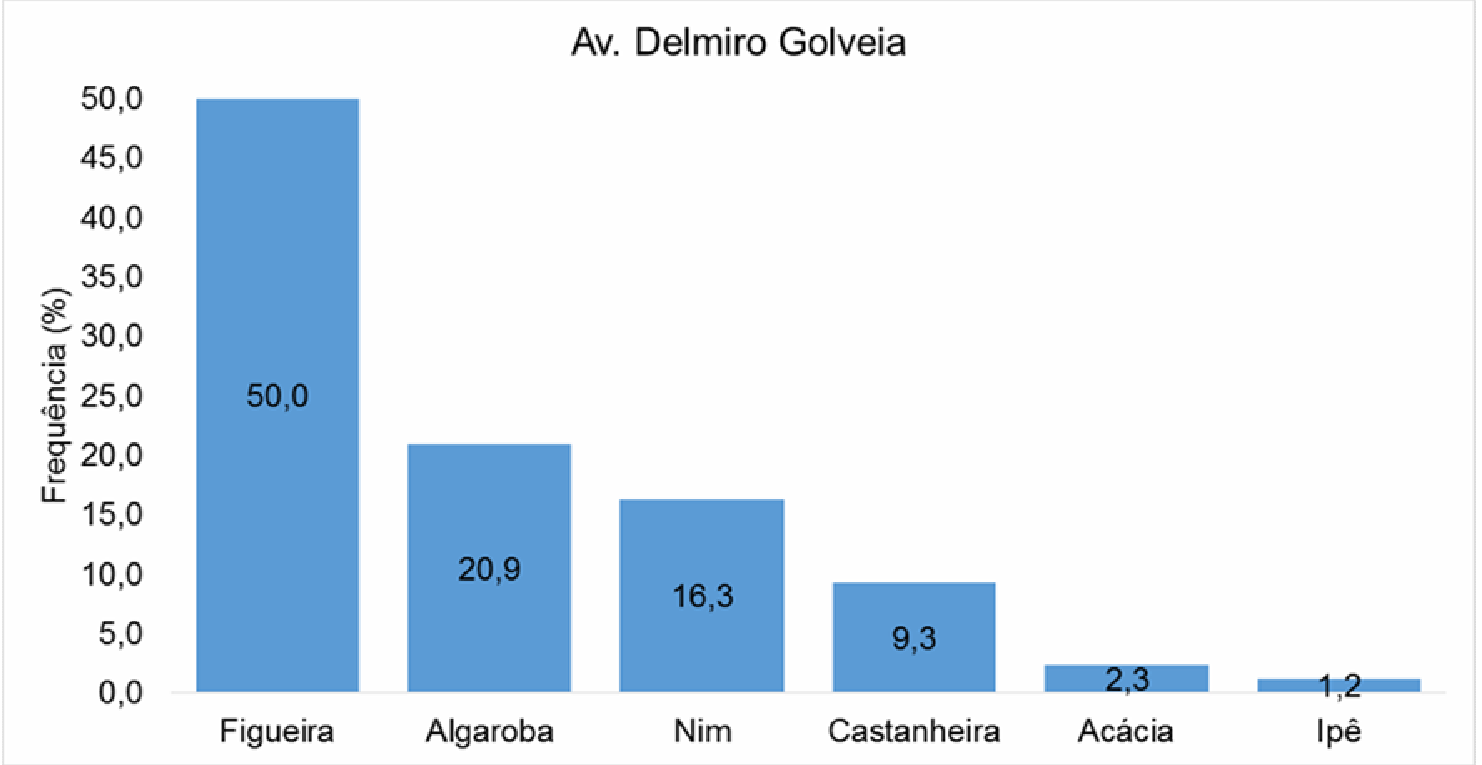

FIGURA 5. Frequência das espécies que compõe a arborização urbana na Avenida Delmiro Gouveia.

$\mathrm{Na}$ avenida Batalha, a arborização é formada por apenas sete espécies arbóreas (Figura 6), sendo relativamente pobre em diversidade de espécies pelas recomendações de GREY \& DENEKE (1986) e MILANO \& DALCIN (2000), tornando-se um risco fitossanitário para o desenvolvimento de pragas e doenças, além de ser esteticamente não recomendado, por desfavorecer a harmonia paisagística. 


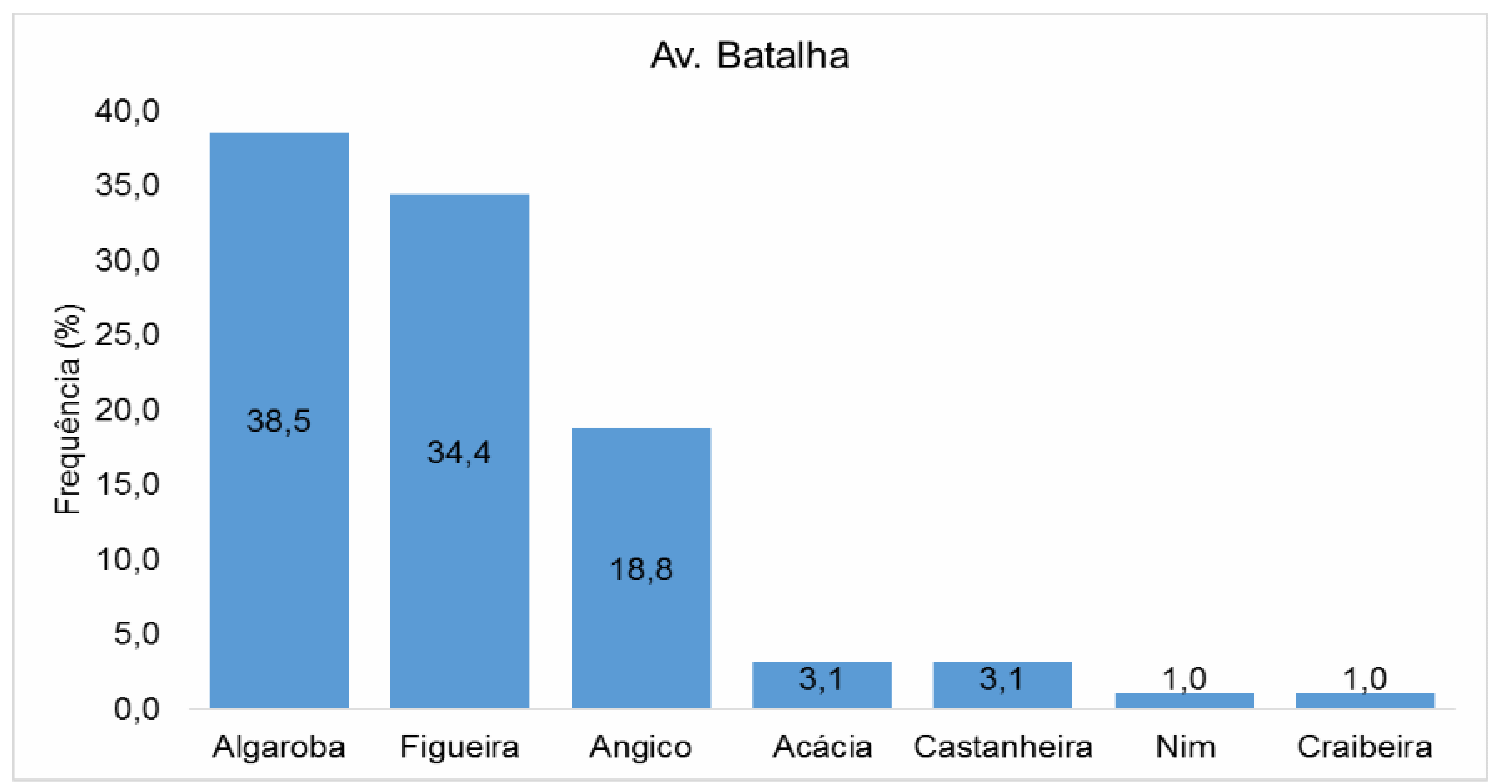

FIGURA 6. Frequência das espécies que compõe a arborização urbana na Avenida Batalha.

As principais espécies identificadas na Avenida Batalha foram: algaroba (Prosopis juliflora (Sw) DC) (38,5\%); figueira (Ficus benjamina) (34,4\%); angico (Anadenanthera macrocarpa (Benth.) Brenan) (18,8\%); acácia amarela (Acacia farnesiana) (3,1\%); castanheira (31,1\%); nim (Azadirachta indica) $(1,0 \%)$ e craibeira (Tabebuia aurea) (1,0\%) (Figura 6). A algaroba (Prosopis juliflora (Sw) DC) e a figueira (Ficus benjamina) continuam, também nesta avenida, dominando o estrato arbóreo urbano na cidade, juntas respondem por $72,9 \%$.

A algaroba (Prosopis juliflora (Sw) DC) é uma espécie exótica invasora agressiva que rapidamente se adaptou as condições edafoclimáticas do semiárido. PEGADO et al., (2006) verificaram que os impactos causados pela algaroba foram sentidos tanto na estrutura, quanto na diversidade biológica da comunidade, competindo com as espécies nativas, afetando severamente a composição florística, a diversidade e a estrutura das comunidades autóctones invadidas. Sendo assim, torna-se importante evitar a utilização dessa espécie na arborização urbana, por ser uma espécie exótica que tem trazido comprovados prejuízos ao bioma caatinga, desta forma diminui-se seu potencial de dispersão pelos seres humanos e animais.

Segundo GOMES (1961) e AZEVEDO (1982) citados por PEGADO et al., (2006) a algaroba foi introduzida no Semiárido nordestino no início da década de 40 como uma alternativa econômica, por ser adaptada às condições semiáridas e apresentar múltiplos usos como, produtora de lenha, madeira, forragem e outros produtos. Entretanto, as inúmeras qualidades e a facilidade de adaptação e dispersão transformaram a solução em um novo problema para o Semiárido (PEGADO et al., 2006).

$\mathrm{Na}$ arborização urbana da Avenida Sergipe tem-se o maior problema de diversidade de espécies, sendo formada por apenas quatro espécies e destas, as duas primeiras craibeira (Tabebuia aurea) e algaroba (Prosopis juliflora (Sw) DC) juntas respondem por $88 \%$ do total de todas as árvores (Figura 7). 


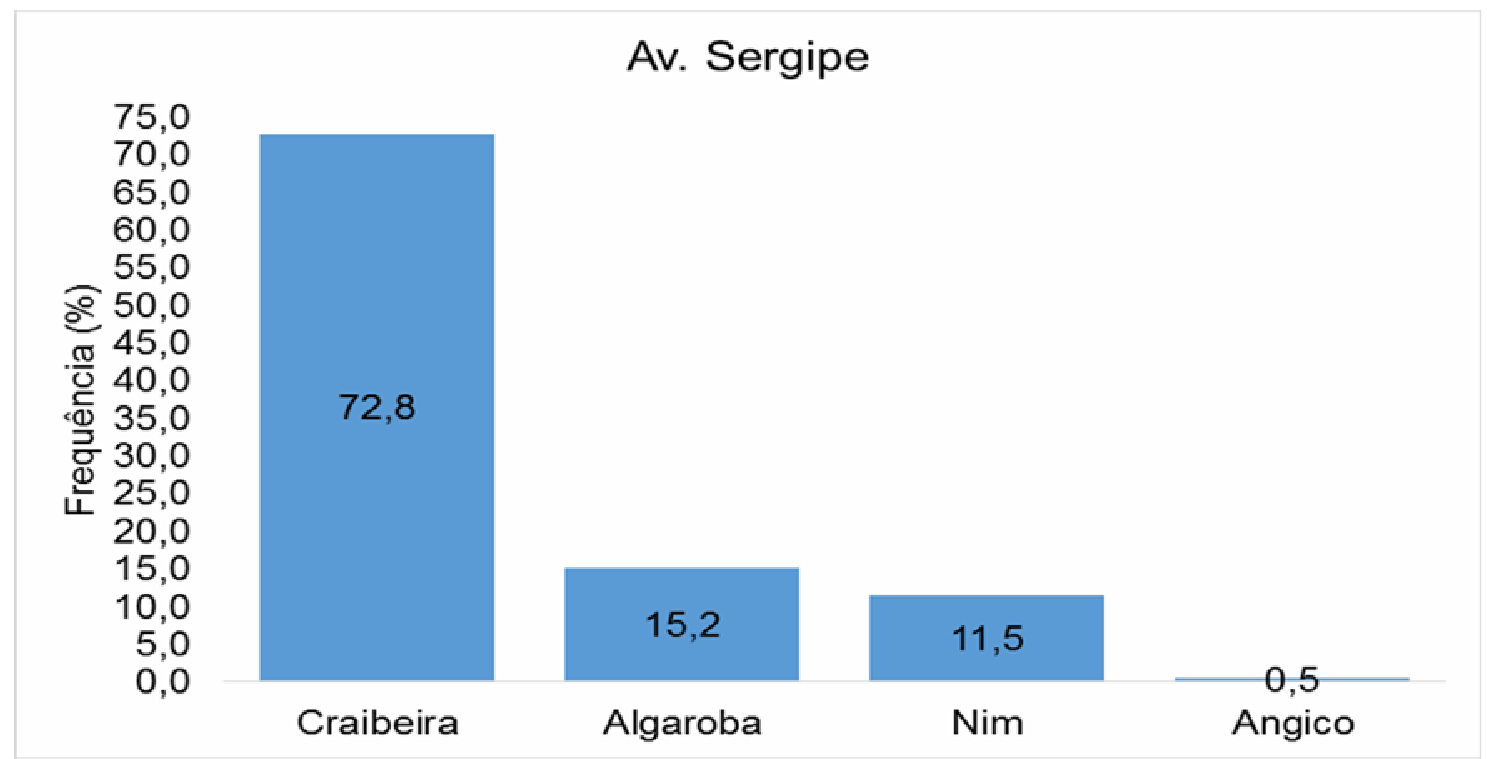

FIGURA 7. Frequência das espécies que compõe a arborização urbana na Avenida Sergipe em Piranhas - AL.

Em relação às espécies exóticas o problema é menor na avenida Sergipe, pois a craibeira (Tabebuia aurea) é uma espécie nativa, símbolo do Estado de Alagoas e responde por $72,8 \%$ das árvores plantadas, mas atenção deve ser dada ao avanço nos plantios de algaroba (Prosopis juliflora (Sw) DC), hoje já com 15,2\% e com o nim (Azadirachta indica) que tem 11,5\% e também tem se adaptado bem ao semiárido (Figura 7).

$\mathrm{Na}$ avenida Rio São Francisco tem-se uma composição da arborização urbana com 6 espécies, com destaque para a algaroba (45,7\%), craibeira (Tabebuia aurea) $(30,9 \%)$ e sombreiro (Clitoria fairchildiana) $(20,6 \%)$ que juntas respondem por $97,2 \%$ do total de árvores (Figura 8). A soma das espécies exótica (algaroba, sombreiro, nim e mangueira) alcança $68,0 \%$ do total de árvores plantadas, evidenciando a necessidade de aumentar a diversidade de espécies e o número de espécies nativas nesta arborização.

A craibeia (Tabebuia aurea) é a espécie nativa mais frequente encontrada de forma geral na arborização urbana da cidade de Piranhas, isso possivelmente se deve ao fato de ter uma florada atraente de cor amarela, apresentar rápido crescimento quando se compara à outras espécies nativas, fácil dispersão e elevado poder germinativo das sementes. Segundo MAIA (2004) a craibeira (Tabebuia aurea) pode atingir de $10-15 \mathrm{~m}$ de altura e no Brasil ocorre no Cerrado, Caatinga, Pantanal Matogrossense. Ela possui múltiplos usos, sua madeira é resistente, podendo ser usada na construção civil, carpintaria, fabricação de carvão, móveis, entre outros. 


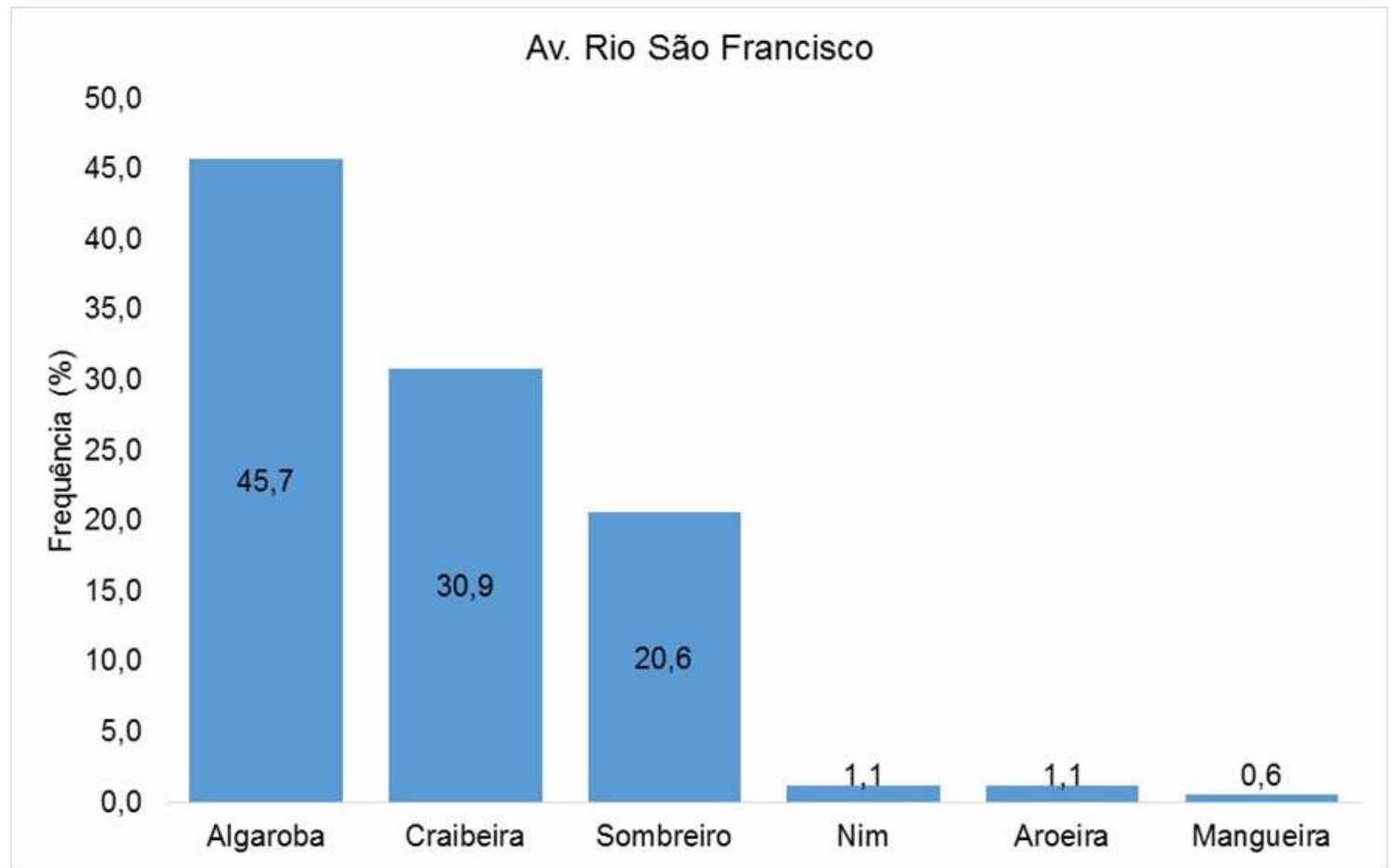

FIGURA 8. Frequência das espécies que compõe a arborização urbana na Avenida Rio São Francisco.

A necessidade de replantio nas avenidas avaliadas é considerável, ao todo são 157 locais que necessitam de uma nova árvore, isso representa $28,7 \%$ do total de árvores de arborização urbana de Piranhas (Figura 9). Esses locais para replantio podem ser utilizados para enriquecimento da diversidade de espécies arbóreas. Para tanto, há necessidade da realização de um estudo florístico e fitossociológico da região, para conhecer as espécies nativas, a serem introduzidas. Além disso, o plantio deve priorizar, na medida do possível, as espécies de maior valor de importância, que pode ser obtido somando-se para cada espécie os valores relativos de abundância (densidade), dominância e frequência (HACK et al., 2005).

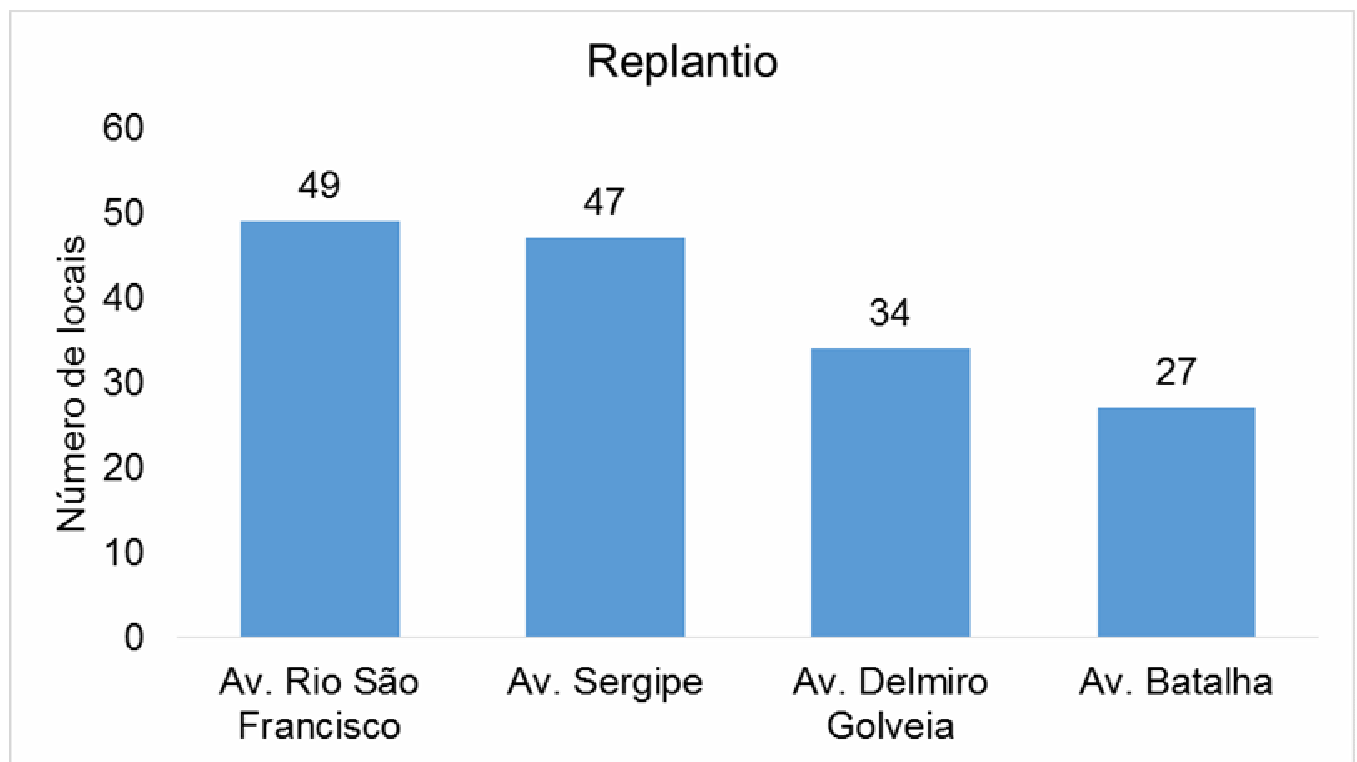

FIGURA 9. Necessidade de replantio nas avenidas Rio São Francisco, Sergipe, Delmiro Gouveia e Batalha. 
A supressão das árvores de espécies exóticas invasoras é uma solução drástica para plantar as espécies nativas e diversificar o componente arbóreo da cidade, mas isso deve ser feito com cautela para não desfigurar toda arborização, já que estas espécies são maioria. Devendo, primeiramente realizar os replantios necessários e suprimir as exóticas seguindo um planejamento que pode levar em consideração o acometimento por pragas e doenças, danificação de calçadas, problema com a rede elétrica, entre outros fatores que devem ser cuidadosamente analisados.

Os principais problemas encontrados nas avenidas Rio São Francisco, Sergipe, Delmiro Gouveia e Batalha foram raízes danificando calçadas, necessidade de replantio, alguns locais com problemas com a rede elétrica e a enorme quantidade de espécies exóticas compondo a arborização da paisagem urbana de Piranhas, que muitas vezes são escolhidas por sua capacidade de adaptação, eficiente formação de sombra e rápido desenvolvimento.

\section{CONCLUSÕES}

A arborização urbana nas principais avenidas no município de Piranhas é composta por espécies exóticas invasoras, com exceção da Avenida Sergipe que apresenta elevada quantidade de craibeiras (Tabebuia aurea).

A diversidade de espécies que compõe a arborização da paisagem urbana de Piranhas é pequena, trazendo efeito estético negativo e favorece o desenvolvimento de doenças e pragas nas árvores.

Os principais problemas encontrados na arborização urbana das avenidas Rio São Francisco, Sergipe, Delmiro Gouveia e Batalha foram raízes danificando calçadas, necessidade de replantio, problemas com a rede elétrica e a quantidade de espécies exóticas.

\section{REFERÊNCIAS}

AB' SABER, A. N. Domínios morfo-climáticos e solos do Brasil. In: ALVARES V., V. H.; FONTES, L. E. F.; FONTES, M. P. F. (eds.). O solo nos grandes domínios morfoclimáticos do Brasil e o desenvolvimento sustentável. Viçosa-MG, SBCS; UFV, DCS, 1996.930p.

ALBERTIN, R. M.; DE ANGELIS, R.; DE ANGELIS NETO, G.; DE ANGELIS, B. L. D. Diagnóstico quali-quantitativo da arborização viária de Nova Esperança, Paraná, Brasil, Revista da Sociedade Brasileira de Arborização Urbana, Piracicaba, SP, v.6, n.3, p.128-148, 2011.

ALMEIDA, J. R.; BARBOSA, C. G. Diagnóstico da arborização urbana da cidade de Cacoal-RO, Revista da Sociedade Brasileira de Arborização Urbana, Piracicaba, SP, v.5, n.1, p.61-81, 2010.

BLUM, C. T. Espécies exóticas invasoras na arborização de vias públicas de Maringá-PR. Revista da Sociedade Brasileira de Arborização Urbana, Piracicaba, v.3, n.2, p.78-97, jun. 2008.

BRAND, K. América do Sul invadida. A crescente ameaça das espécies exóticas invasoras. Programa Global de Espécies Invasoras (GISP), 80p, 2005. 
CARVALHO, A. A.; SILVA, L. F.; LIMA, A. P.; SANTOS, T. P. A inviabiliadade do ficus (ficus benjamina l.) para arborização viária. Anais da XIII Jornada de Ensino, Pesquisa e Extensão - JEPEX 2013 - UFRPE: Recife - PE, 3p, 2013.

COPEL - Companhia Paranaense de Energia. A arborização urbana. Disponível em: < http://www.copel.com/hpcopel/guia_arb/a_arborizacao_urbana.html>, acessado em 26 de novembro de 2016.

GREY, G. W.; DENEKE, F. J.; Urban forestry. New York, John Wiley \& Sons, 1986. $279 \mathrm{p}$.

HACK, C.; LONGHI, S. J.; BOLIGON, A. A.; MURARI, A. B.; PAULESKI, D. T. Análise fitossociológica de um fragmento de floresta estacional decidual no município de Jaguari, RS. Ciência Rural, 35(5), 1083-1091. 2005.

LORENZO, A. B.; BLANCHE, C. A.; QI, Y.; GUIDRY, M. M. Assessing residents' willingness to pay to preserve the community urban forest: a small-city case study. Journal of Arboriculture, v. 26, n. 6, p. 319-324, 2000.

MAIA, G. N. Caatinga. Árvores e arbustos e suas utilidades. $1^{\text {a }}$ edição São Paulo; D \& Z Computação gráfica e editora, 2004.

MELO, R. R.; LIRA FILHO, J. A.; RODOLFO JÚNIOR, F. Diagnóstico qualitativo e quantitativo da arborização urbana no bairro Bivar Olinto, Patos, Paraíba, Revista da Sociedade Brasileira de Arborização Urbana, Piracicaba, SP, v.2, n.1, p.64-80, 2007.

MILANO, M.; DALCIN, E. Arborização de vias públicas. Rio de Janeiro: LIGHT, 2000. 226p.

PEGADO, C. M. A.; ANDRADE, L. A.; FÉLIX, L. P.; PEREIRA, I. M. Efeitos da invasão biológica de algaroba - Prosopis juliflora(Sw.) DC. sobre a composição e a estrutura do estrato arbustivo-arbóreo da caatinga no Município de Monteiro, PB, Brasil. Acta botânica brasileira, 20(4): 887-898. 2006.

PIVETTA, K. F. L.; SILVA FILHO, D. F. Arborização Urbana. Boletim Acadêmico Série Arborização Urbana. UNESP/FCAV/FUNEP, Jaboticabal, SP - 2002, 69p.

SILVA, P. C. G.; MOURA, M. S. B.; KIILL, L. H. P.; BRITO, L. T. L.; PEREIRA, L. A.; SÁ, I. B.; CORREIA, R. C.; TEIXEIRA, A. H, C.; CUNHA, T. J. F.; FILHO, C. G. Caracterização do semiárido brasileiro: fatores naturais e humanos. In: SÁ, I. B.; SILVA, P. C. G., eds. Semiárido brasileiro: pesquisa, desenvolvimento e inovação. Petrolina-PE, Embrapa Semiárido, 2010. 402p.

SILVA, A. G.; GONÇALVES, W. Inventário e Diagnóstico da Arborização da Cidade de Cajuri, MG. Enciclopédia Biosfera, Centro Científico Conhecer, Goiânia, v.8, n.15; p. 1102-1113, 2012. 